\title{
Conciencia obrera y conciencia histórica como referentes sociohistóricos de autogestión en territorios del Cauca indígena
}

\author{
Worker awareness and historical awareness as socio-historical \\ referents of self-management in indigenous Cauca territories
}

Edgar Arboleda Suárez

Auditor gubernamental en la Contraloría General de la República, Contador Público (Universidad del Cauca) con estudios de posgrado en Administración (Universidad del Valle). Magister en Administración, ex catedrático Universidad del Cauca y Fundación Universitaria de Popayán, integrante del grupo de investigación Contabilidad, Sociedad y Desarrollo de la Universidad del Cauca, autor de artículos y ponencias en revistas y eventos académicos sobre contabilidad y gestión.

E-mail: earboleda@unicauca.edu.co

Doi: https://doi.org/10.22267/rceilat.194445.30

\section{Resumen}

El documento presenta el escenario de crisis empresarial experimentado por Industrias Puracé S.A. en la década de los noventa; una antigua empresa dedicada a la explotación de azufre natural en la región Puracé en el Departamento del Cauca, Colombia; la cual es rescatada (o recuperada) por sus trabajadores a través de una nueva nominación simbólica denominada Empresa Minera Indígena del Cauca Emicauca S.A. Se resalta el acervo sociohistórico de los trabajadores en cuanto obreros, aspecto que se expresa en la conciencia de clase obrera y, de otra parte, la conciencia histórica de su condición indígena, como recursos que permiten la emergencia de esta experiencia de autogestión.

Palabras clave: Modernización; Crisis; Conciencia de clase; Conciencia histórica; Autogestión.

\begin{abstract}
The document presents the business crisis situation experienced by Puracé S.A. Industries in the 1990's. This was a company dedicated to the exploitation of natural sulfur in the Puracé region in the Cauca Department in Colombia. The indigenous workers recovered the firm through a new symbolic nomination called the Cauca indigenous mining company Emicauca S.A. The workers socio-historical heritage is highlighted. An aspect that is expressed in the consciousness of the working class and the historical awareness of the indigenous condition, as resources that allow the emergence of this experience of self-management.
\end{abstract}

Palabras clave: Modernization; Crisis; Class consciousness; Historical awareness; Self-management. 
Crisis de Industrias Puracé S.A. y emergencia de Emicauca S.A.

Industrias Puracé S.A. fue una compañía pionera en la explotación, procesamiento y comercialización del azufre natural en Colombia, fundada en la década de 1940 en el marco del modelo cepalino de industrialización para la sustitución de importaciones. La compañía era subsidiaria de Celanesse Colombia S.A., una filial de la multinacional canadiense Celanesse Internacional, la cual había invertido en varias compañías de productos químicos, farmacéuticos y de textiles en el Valle del Cauca. La empresa fue exitosa hasta mediados de la década de 1970, cuando Alfonso López Michelsen (1974-1978) intentó el primer proceso de apertura de la economía, circunstancia que sometió a Industrias Puracé S.A. a la primera experiencia de crisis económica y financiera.

No obstante, es en la década de 1990, mediante el proceso de modernización o apertura económica de César Gaviria Trujillo (1990-1994), cuando Industrias Puracé S.A. experimenta una verdadera crisis financiera. El azufre dejó de ser el recurso escaso en el mercado nacional para constituirse en el producto desechable y abundante de la internacional industria petrolera, situación que generó una caída drástica de los precios en el mercado interno. Lo anterior condujo a una saturación de los inventarios y, en consecuencia, a la iliquidez, el endeudamiento y al abandono definitivo de la compañía por parte de los empresarios.
Este escenario empresarial suscitó una crisis social y económica en todo el oriente caucano, ya que un centenar de trabajadores y sus familias dejaron de percibir sus salarios. El sindicato de la empresa y los comuneros del Resguardo Indígena de Puracé, comunidad a la que pertenecía buena parte de la masa obrera de Industrias Puracé S.A., deciden emprender distintas movilizaciones y protestas pacíficas, como la toma de la Catedral Basílica de Nuestra Señora de la Asunción en Popayán, exigiendo del Gobierno Nacional y de los empresarios la recuperación de la empresa.

Es así como el Gobierno y los empresarios acuerdan entregar mediante concordato los restos de la compañía a los trabajadores, siendo esta la forma de pago de sus acreencias y demás derechos laborales. Lo anterior dio inicio a un nuevo periplo social de los trabajadores indígenas del territorio de $\mathrm{Pu}$ racé bajo la condición de trabajadores autogestores, en el marco de las nuevas lógicas estratégicas del capitalismo productivo y financiero, según las cuales, los trabajadores deben constituirse en "inversionistas y empresarios de sí", como auténticas comunidades de trabajadores autogestores.

El escenario de crisis culminó en 1998 con la liquidación definitiva de la compañía y el surgimiento de una nueva empresa por parte de los trabajadores y la comunidad del Resguardo Indígena de Puracé, a través de la constitución de la Empresa Minera Indígena del Cauca S.A. - Emicauca S.A. (Calle, 2009). Frente a estos hechos se formula el siguiente interrogante: ¿Qué 
factores sociohistóricos determinaron el accionar social de los actores en la constitución de un nuevo emprendimiento empresarial denominado Emicauca S.A.? Se trata de escudriñar el pasado sociohistórico que determinó el proceso de recuperación de Industrias Puracé S.A., como un fenómeno de actuaciones recíprocas entre trabajadores y comuneros del Resguardo Indígena de Puracé.

\section{Conciencia de clase obrera en el accionar social del obrero indígena}

En su obra Salario, precio y ganancia, Marx (1954) describe la relación conflictiva existente entre capital y trabajo al interior de la sociedad moderna. El autor hace alusión a la resistencia de los obreros a la rebaja de sus salarios y de otra parte, a la oposición a su incremento por parte de los empresarios o dueños del capital. En estas circunstancias de conflicto entre clases sociales antagónicas ${ }^{1}$, los trabajadores proceden a organizarse y luchar por sus salarios y mejores condiciones laborales y de subsistencia.

En el caso de los trabajadores de Industrias Puracé S.A., su organización y lucha por mejores salarios y condiciones de subsistencia inicia tiempo después de su transformación

1. Marx (1954), se refiere a la oposición de intereses entre propietarios del capital y trabajadores, los primeros intentando arrancar de los segundos el mayor nivel de plusvalía para asegurar su acumulación capitalista y los segundos procurando obtener el mayor nivel de salario posible que les garantice el nivel de subsistencia. de indígenas trabajadores del campo en obreros mineros. Su transformación ideológica comienza desde el instante en que los indígenas son colocados frente a un sistema productivo diferente y se consolida en el momento en que se representan a sí mismos como miembros de la clase obrera. En esta representación de sí como clase obrera influyen tres factores fundamentales: primero, la conciencia de clase que alcanzan algunos de los trabajadores al interior del nuevo proceso productivo en su condición de obreros; segundo, el grado de concientización que desarrollan algunos de los obreros de Industrias Puracé S.A. al entrar en contacto con otras organizaciones de trabajadores a nivel nacional y, tercero, el referente sociohistórico en el cual se encuentran atrapados los obreros en su condición de comuneros en territorios del Cauca indígena.

No obstante, el grado de organización y lucha de los obreros de Industrias Puracé S.A. no pudo ser posible sin una representación previa como clase social "para sí". Marx realiza una distinción del concepto de clase social "en sî" y clase social "para sí”, afirmando que millones de familias pueden vivir en condiciones de existencia muy diferentes entre sí, oponiendo entre ellas modos de vivir, intereses y culturas diferentes, situación que podría constituirles en clases sociales "en sí". Sin embargo, dichos grupos sociales adquieren la categoría de clases sociales "para sí" solo cuando articulan y constituyen identidades reciprocas sobre intereses particulares. Es este último aspecto, el vínculo consciente 
de una clase "en sí" a un conjunto de intereses objetivos particulares, lo que se constituye en una conciencia de clase "para sí”. Esta conciencia de clase "para sí" conlleva a que se instituya en la sociedad y en el interior de las organizaciones modernas grupos de poder específicos (Ríos, 1998), los cuales se organizan para emprender la lucha política, visibilizando de esta manera sus intereses. Es así como en el interior del modo de producción capitalista se exponen plenamente dos clases sociales "en sí": obreros y dueños del capital".

Ahora bien, existen dos etapas subsecuentes en el proceso de distinción de clases sociales "en sí” y el desarrollo de una conciencia de clase social "para sí". Se trata de dos etapas, la primera de ellas referida a la distinción entre clases según las circunstancias materiales; la segunda relacionada con el desarrollo de una conciencia de clase respecto a intereses propios o específicos. Las clases sociales se distinguen unas respecto a otras según el lugar que ocupan en la organización socioeconómica en la sociedad y de acuerdo a las relaciones sociales que a partir de dichas circunstancias socioeconómicas establecen. Sin embargo, es el desarrollo de una conciencia reflexiva respecto a sus circunstancias materiales lo que permite que adopten una conciencia plena de clase. Es en este segundo momento en el que una clase social toma conciencia de sí respecto a sus intereses, adquiriendo el verdadero calificativo de clase social.

En el caso de los obreros de Industrias Puracé S.A., existe una distinción de clase desde el momento en que los indígenas dejan de ser labriegos de la tierra y se convierten en obreros de la industria minera. Esta distinción se evidencia en los indígenas que abandonan la tierra como su principal medio de producción y se convierten en obreros "libres", dispuestos a vender su fuerza de trabajo bajo una nueva condición de subordinación respecto a los dueños del capital (los dueños de Celanese Internacional, Celanese de Colombia S.A. e Industrias Puracé S.A.). No obstante, dicha distinción de clase solo se concreta en el instante en que los obreros adquieren una conciencia de clase "para sí", es decir, cuando identifican plenamente sus intereses y proceden a generar una identidad como clase social obrera, procediendo a organizarse y luchar políticamente a través del sindicato. Esta conciencia de clase puede percibirse en el relato de uno de los obreros de la época ${ }^{2}$, quien en la obra de Cajas (1982: 80) ${ }^{3}$ afirma:

Nosotros nos damos cuenta y somos conscientes del papel que nos toca jugar como obreros, que no quiere decir que nos creamos mayormente superiores a los compañeros indígenas, lo que pasa es que hemos entrado en un nivel de conocimiento de las cosas que antes no teníamos, en veinte años de trabajo yo al menos he comprendido más cosas que cuando

2. Se trata de la década de 1980, por lo tanto, los relatos no visibilizan la conciencia social que pudo germinar en los primeros años de 1950, época en que se constituye el sindicato en Industrias Puracé S.A.

3. En referencia al trabajo monográfico titulado Industrias Puracé S.A.: sobre el proceso de transformación de indígenas en obreros y crisis ambiental. 
estaba en el resguardo trabajando la tierra. Aquí se conoce de cerca lo que es la clase capitalista, y la lucha que hay que dar no solo por el aumento de salarios, sino también por el futuro de una vida mejor para los hijos y para todo el pueblo. Ahora uno entiende mejor que la solución no es que le titulen un pedazo de tierra, porque al fin y al cabo sino se tiene plata para mejorarla se queda en las mismas o solo sirve para calmar el estómago por unos meses o a mucho, iy eso dando gracias un par de años con las cosechas que se pueda sacarle!

Es el mismo caso de que si con el aumento de salarios en la empresa se nos arreglara el problema del todo a los obreros, ino señor!, el problema es que unos somos pobres y otros son ricos, y que las cosas de la naturaleza están mal repartidas.

Este proceso hacia el desarrollo de una conciencia de clase "para sí” por parte de los obreros de Industrias $\mathrm{Pu}$ racé S.A. logra fructificar en 1958, año en el cual los trabajadores reciben por parte del gobierno nacional aval para organizarse en sindicato ${ }^{4}$. Este hecho no fue bien recibido por parte de los dueños de la empresa quienes en el afán de defensa de sus intereses de clase, proceden a calificar el accionar

4. Para Marx, el proceso organizativo a partir del desarrollo de una conciencia de clase por parte de los trabajadores es un proyecto de mayor envergadura a la simple conformación de un sindicato, este implica el accionar social en torno a la toma de poder del Estado, con miras a la instauración de una organización social de estirpe socialista $\mathrm{y}$, posteriormente comunista. obrero como el rompimiento de las "buenas relaciones" entre patronos y trabajadores. Así se desprende del relato de uno de los informantes en la obra de Cajas (1982: 96):

Claro que esto no se dio de la noche a la mañana, sino que resultó luego de un buen tiempo de trabajar la base. Solo fue hasta el año de 1958, cuando logramos fundar el sindicato, para sorpresa de los patronos que ahí mismo brincaron diciendo que la cosa ahora si era pa joderse, porque Industrias Puracé por la fuerza no iba a darnos nada, que los obreros éramos muy pendejos por dejarnos mangonear de subversivos de Popayán ${ }^{5}$ y de otros que ya tenían localizados en la empresa y que iban a despedir.

A pesar de las estrategias emprendidas por los empresarios el sindicato logrará consolidarse, constituyéndose en una fuerza de poder político capaz de sobrepasar las propias fronteras borrosas de la empresa. El vínculo con las centrales obreras de Colombia imprimirá en los miembros del sindicato una perspectiva del conflicto diferente, pues comprenderán que la lucha entre capital y trabajo solo puede concretarse sobre la base de una organización superior de los trabajadores, por ello, su futuro estará vinculado al movimiento obrero nacional a través de la Unión de Trabajadores del Cauca (Utracauca),

5. El informante se refiere al apoyo de la clase trabajadora de Popayán vinculada a las centrales obreras, como la Unión de Trabajadores del Cauca, filial de la Unión de Trabajadores de Colombia. 
filial de la Unión de Trabajadores de Colombia (UTC) ${ }^{6}$.

El vínculo del sindicato de Industrias Puracé S.A. con las centrales obreras a nivel nacional permitió a los trabajadores una comprensión más amplia del conflicto entre capital y trabajo al interior del modo de producción capitalista. La lucha política dejó de ser un asunto exclusivo relacionado con el incremento del salario para constituirse en una disputa por el poder político del Estado. Desde el punto de vista marxista, los trabajadores apostaron por el cambio del modelo económico imperante, procurando acceder a diferentes esferas del poder político del Estado, a través de las diferentes organizaciones, movimientos y partidos políticos de los trabajadores.

A nivel local, los trabajadores de Industrias Puracé S.A. vinculados a la organización sindical fueron constituyéndose en líderes y autogestores entre los habitantes de la comunidad puraceña, emprendedores de acciones colectivas relacionadas con el mantenimiento y construcción de obras públicas, la gestión de un fondo de empleados, una cooperativa de comercialización, tiendas comunitarias y asociaciones de productores. Es decir, no solo se consti-

6. La Unión de Trabajadores de Colombia (UTC) se fundó en junio de 1946, en oposición a la Central de Trabajadores de Colombia (CTC), institución creada en agosto de 1935. El objetivo de los empresarios antioqueños era entenderse directamente con sus trabajadores, contrarrestando el intervencionismo estatal y el comunismo creciente, aspectos predominantes en el accionar de la CTC. tuyó en un sindicato para el ejercicio de la acción política al interior de Industrias Puracé S.A. vinculado a la disputa del poder político del Estado a través de las organizaciones políticas de las centrales obreras, sino que, además, avanzó como organización sindical con capacidad para emprender acciones colectivas de autogestión económica a nivel local.

Hechos que se configuran en accionar social de los obreros indígenas de Industrias Puracé S.A. a partir del desarrollo de una conciencia de clase "para sí”, y que fueron determinantes para el accionar social de autogestión frente al escenario de crisis empresarial experimentado a partir de la década de los noventa. No obstante, como veremos más adelante, este accionar social a partir del desarrollo de una conciencia de clase "para sí" va a estar complementado por el pasado sociohistórico que habita entre los trabajadores desde su condición indígena, en particular, la impronta del pasado común en cuanto sujetos sociales pertenecientes a una minoría étnica sometida a prácticas de explotación y despojo desde los tiempos de la conquista y la colonia.

\section{Conciencia histórica de la condición indígena en el accionar social del obrero}

A esta conciencia de clase de los obreros indígenas de Industrias Puracé S.A. le antecede el desarrollo de una conciencia histórica en territorios del Cauca indígena. Se hace referencia a una conciencia histórica de la condición indígena promovida a principios del siglo XX por dirigentes como Manuel Quintín Lame Chantre (1883- 
1967), un descendiente de indígenas paeces nacido en la hacienda San Isidro - Popayán", quien en el año 1910 irrumpe en el escenario nacional proclamándose como “jefe, representante y defensor general" de los Cabildos indígenas de Pitayó, Jambaló, Toribío, Poblazón, Cajibío, Pandiguando y Puracé $^{8}$ (Castrillón, 1973).

Quintín Lame es considerado un autodidacta que "aprendió por su propia cuenta” el ejercicio de la lectura y la escritura pues no recibió educación formal alguna; el mismo Lame comenta en uno de los apartes de su obra inédita Los pensamientos del indio que se edu-

7. Respecto a la vida de Manuel Quintín Lame Chantre, son pertinentes los datos biográficos otorgados por Castillo (2004: 16), quien a manera de pie de página enuncia lo siguiente: "Este dato es tomado de su propio texto. Es posible que no sea exacto pues la fecha de nacimiento no es siempre recordada fielmente por indígenas y campesinos. En la parroquia de Puracé hay una partida de bautismo (Libro 13, 26 de octubre de 1880 y bautizado el 12 de diciembre) de un niño de nombre Juan Quintín Lame, nacido el mismo año. Sus padres son Mariano Lame y Dolores Chantre, los mismos de Manuel Quintín Lame. Es muy probable que se trate de la misma persona”. Romero (2006) por su parte, describe lo siguiente: Quintín Lame fue un pensador indigenista y dirigente político abanderado de los derechos de los indígenas, nacido en el Borbollón, Hacienda la Polindara, en cercanías a Popayán el 26 de octubre de 1880 y bautizado en la parroquia de San Miguel Arcángel, en Puracé.

8. Sin desconocer a la Cacica Gaitana y Juan Tama, distinguidos dirigentes de los siglos XVI y XVII quienes en la memoria histórica de los indígenas Manuel Quintín Lame Chantre (1883-1967) reclama. có dentro de las selvas colombianas ${ }^{9}$, las dificultades que tuvo para acceder a la educación formal en la Colombia de su época (Lame, 2004: 146):

Yo no puedo enorgullecerme con sofismas de que hice determinados estudios en una escuela, en un colegio, etc; pues mi colegio fue la fe con un entusiasmo incansable, porque le pedí a mi padre señor Don Mariano Lame la educación, es decir, me mandara a la escuela y me consiguió fue una pala, un hacha, un machete, una hoz y un agüinche y me mando con siete hermanos a socalar y derribar montaña, pero yo con ese entusiasmo que sobrepujaba en mi interior me llego el pensamiento de que debía escribir en una tabla con un carbón y que la pluma debía ser dicha aguja en la hoja de un árbol, la muestra fue que a sabiendas le tomé varios papeles que tenía mi anciano tío Leonardo Chantre.

Ahora bien, ¿de dónde pudo proceder este interés de transformación de Manuel Quintín Lame hacia una condición de indígena ilustrado, en un entorno hostil, siendo que al indígena de la época se le impedía acudir siquiera a la escuela? Tal acercamiento parece proceder de la experiencia de Manuel Quintín Lame en diferentes contextos de su vida, pues si bien no accedió a educación formal alguna,

9. En su interés por difundir sus ideas, Quintín Lame escribió una serie de artículos políticos, un libro filosófico político, realizó entrevistas en la prensa nacional y redactó cientos de memoriales, cartas y telegramas; se destaca el libro los pensamientos del indio que se educó dentro de las selvas colombianas, culminado en 1939. 
tuvo momentos de interrelación comunicativa alfabetizadora en contextos de instrucción permanentes, recibiendo a través de ellos una formación transcultural $^{10}$ de la naturaleza objetiva de las cosas y adquiriendo habilidades sobre diversos temas a partir del ejercicio de la lectura y la escritura. Esta condición de indígena ilustrado a la que se refiere Romero (2006), permitió a Quintín Lame concebir la educación como un medio de ascenso y liberación del oscurantismo en que se encontraba el indígena en su territorio a finales del siglo XIX, a la vez que vislumbró en la escritura un mecanismo de incitación y lucha popular de su pueblo indígena.

No obstante, la labor de Manuel Quintín Lame no estuvo precisamente en la agricultura, más bien se desempeñó como abogado, suscitando desde este campo un conjunto de nuevas ideas, modificando las ya existentes, estableciendo nuevas consideraciones sobre los indígenas, utilizando las leyes en función de la causa y defensa de sus derechos, ejerciendo desde este tipo de saber la práctica de la política. Ahora bien, ¿qué factores materiales pudieron incidir en este accionar reflexivo de Manuel Quintín Lame Chantre, al punto de constituirse en un actor político importante en las primeras

10. Con el termino "transcultural" se hace referencia a la relación de Quintín Lame "[...] con la experiencia histórica de ser "observado" y clasificado como "otroindio" y sus mecanismos de autorepresentación, los cuales estuvieron inmersos dentro de las relaciones de dominación y resistencia y formas de traducción, ambivalencia, no originalidad y reinvención cultural" (Espinosa, 2003: 143). décadas del siglo XX en el Cauca? Castillo (2004: 17) comenta al menos dos razones fundamentales: "[...] la expropiación permanente de las tierras de parcialidad por parte de los colonos, hacendados y empresarios rurales expansionistas y la condición humillante de semiesclavitud en la cual vivían los indios terrazgueros y que persiste hasta el día de hoy en la misma forma y en otras formas".

El proceso de expansión del moderno sistema mundo y la incorporación de territorios locales a las lógicas de dicho sistema conllevaron al surgimiento de una clase agraria y comercial en todo el territorio nacional, constituida por sujetos cuya distinción es su espíritu de libre empresa, a quienes se les puede describir como colonizadores y expansionistas. Este es el caso de Ignacio Muñoz ${ }^{11}$, uno de los grandes hacendados del Cauca a principios del siglo XX, de quien Castillo (2004: 18) afirma lo siguiente:

Ignacio Muñoz, dueño de la hacienda San Isidro y patrón de Quintín Lame y de sus padres, fue uno de los principales exponentes de este nuevo tipo de hombre. "Aunque había tenido solo tres años de enseñanza llegó a imponerse hasta ser el hombre más rico

11. Ignacio Muñoz fue también un gran empresario, quien en 1905 llegó a fundar en compañía de José María Sierra, Pedro Jaramillo, José Jesús Salazar, Nemesio Camacho y otros hacendados y comerciantes de Bogotá y Manizales, la "Sociedad Bancaria Anónima de capital limitado denominada Banco Central”, al tiempo que lideraba en compañía de inversionistas extranjeros la construcción del Ferrocarril del Cauca o Ferrocarril del Pacífico (Álvarez, 2001). 
de todo el Cauca. Llego a poseer haciendas en Pance y Piedra Grande (al sur de Cali) y La Chamba (al norte del actual Departamento del Cauca) hasta lo alto de la cordillera central y otras haciendas en diferentes lugares del Departamento. iEn tierras propias de ganadería llegó a tener 30.000! iSolo en la región de Puracé y San Isidro descuajó 11.000 hectáreas de montaña [...]! La barrera principal que se oponía a la "inconmensurable capacidad de acción” y al espíritu expansionista de hacendados como Muñoz eran los Resguardos. Su repartición se convirtió, entonces, en una exigencia del "progreso". A principios del siglo el general Reyes decreto acelerar las reparticiones y todos los gobernadores y alcaldes, en representación de los intereses de clase de los terratenientes y comerciantes, se embarcaron en una campaña abierta para lograrlo en el tiempo más corto posible. La Ley 104 de 1919 fijó castigos para los indígenas que "estorbaban” la repartición de los Resguardos y dicto medidas para que esta se acelerara.

Este proceso expansionista de terratenientes agrarios en calidad de empresarios y comerciantes terminó por generar un nuevo fenómeno de violencia, todo como consecuencia de la fuerte presión ejercida por los grandes hacendados sobre el territorio de los Resguardos. Al mismo tiempo que se establecían las nuevas relaciones sociales de producción al interior de las haciendas entre terratenientes capitalistas, mayordomos e indígenas terrazgueros. De lo anterior se derivó una gran masa de terrazgueros en buena parte del Departamento, indígenas despojados de su tierra quienes se veían forzados a vivir al interior de las haciendas en condiciones de semiesclavitud y servidumbre.

Este carácter inhumano que caracteriza las relaciones sociales de producción al interior de las grandes haciendas explica en gran medida el comportamiento particular y subjetivo del propio Quintín Lame, como un sujeto producto de las circunstancias materiales de su época, al mismo tiempo que produce reflexivamente las nuevas circunstancias organizacionales del conflicto y contradicciones. En uno de los acápites de su obra, Quintín Lame (2004: 162) afirmará:

La experiencia tiene dos poderosos muros, el uno es visible y el otro es invisible, muros que me han servido de trincheras poderosas para favorecerme de la metralla de mi enemigo en el campo de encarnizados combates en lo material, en lo civil y en lo moral; pero para esto se necesita tener una memoria feliz y única; el primer muro es donde está depositado todas las acciones que le danzaron al hombre desde el momento en que tuvo uso de razón, como el indígena que nunca se olvida del blanco que le pagó a su padre de obra y lo ultrajó de palabra, a su hermano, a su esposa, él no dice nada, pero en el interior conserva el pensamiento del gallo de pelea y se venga haciéndole salir una úlcera en que dicen en su lenguaje algunas personas maleficio. El blanco le roba la finca al indígena, emborrachándolo; haciéndole firmar documentos de débito sin deberle; llevándolo ante los jueces para seguirle la ejecución, y el juez se presta diciéndole a uno: "es mejor que le pague"; contradice uno, "pero yo qué le pago si no le debo nada"; le ordenan al indio: "nombre abogado". El indio nombra su abogado 
pero el hurtador, ladrón o estafador se une con el abogado del indio que desea defender su derecho o propiedad, o semoviente, etc, y lo requiere diciéndole "partimos el dinero que estoy ganando y dame el pleito ganado, porque entre los blancos o mestizos tenemos que favorecernos, el indio ieso que!”, etc.

En el relato de Quintín Lame se describen todos los actores y mecanismos sociales de opresión y explotación de los que fue objeto el indígena en las primeras décadas del siglo XX, se trata de los representantes más “dignos” de la sociedad culta y civilizada representada en los hacendados, mayordomos, comerciantes, jueces y abogados; quienes usurpan la tierra y establecen sobre los indígenas nuevas relaciones sociales de producción. El muro visible planteado por Lame es la realidad material concreta que describe la condición humana del trabajador indígena al interior de la hacienda. Lame se describe como un indígena con conciencia histórica respecto al despojo del que ha sido objeto por más de cuatrocientos años, al mismo tiempo que discierne a través del uso de la razón el contenido mismo de la palabra, redescubriendo en este instrumento del lenguaje su humanidad $^{12}$ y el tratamiento inhumano del que ha sido objeto el indígena por parte del "blanco" opresor.

12. Lame expresa en algunos apartes de su escrito la transformación que sufrió al pasar de un estado de animalidad a uno de humanidad, metafóricamente, el paso de un estado de ignorancia a uno de conocimiento y profunda espiritualidad.
La postura de Quintín Lame trasciende el propio materialismo histórico pues no se trata de la apropiación privada de la tierra y del establecimiento de nuevas relaciones sociales de producción exclusivamente, sino del despojo ampliado del que han sido objeto los indígenas en aspectos propios de su cultura ${ }^{13}$, es decir, lo simbólico representado en las leyes, costumbres, formas económicas de vida, cosmovisiones y religiones propias. Es por ello que Quintín Lame emprende entre los años 1910 y $1960^{14}$ una campaña edu-

13. Esta postura histórica de Quintín Lame es en términos de Espinosa (2003: 144), un pensamiento transcultural, al mismo tiempo que descolonizador: "No es que sea "descolonizado", sino que se convierte en una forma de denuncia persistente a las tecnologías coloniales de poder, que han asumido históricamente la forma de unas relaciones jerárquicas entre blancos, mestizos e indios -o negros y blancos, incluyendo toda la gama de categorías socioraciales institucionalizada en las colonias hispanoamericanas".

14. La acción política de Manuel Quintín Lame coincide con una serie de hechos importantes, como el preludio del levantamiento social en el campo a través de la huelga de trabajadores de la agroindustria bananera en la costa atlántica y el posterior asesinato de obreros en lo que se conoce como la "masacre de las bananeras" en 1928, el ascenso del Partido Liberal al poder en 1930, la agudización del conflicto entre liberales y conservadores entre 1948 y 1953, la alternancia del poder por parte de los partidos Liberal y Conservador en el llamado Frente Nacional entre los años 1958 y 1974, el recrudecimiento de la violencia política y el posterior surgimiento de las guerrillas liberales y comunistas y el proceso de modernización del país a partir de una etapa de industrialización orienta- 
cativa, de concientización, agitación y lucha respecto a la condición indígena, las cuales se sustentan en los siguientes puntos (Castillo, 2004: 20):

(1) defensa de las parcialidades y oposición militante a las leyes de división y repartición de las mismas; (2) consolidación del Cabildo indígena como centro de autoridad y base de organización; (3) recuperación de las tierras perdidas a manos de los terratenientes y desconocimiento de todos los títulos que no se basaran en cedulas reales; (4) liberación de los terrazgueros, mediante la negación a pagar terraje o cualquier otro tributo personal; y (5) afirmación de los valores culturales indígenas y rechazo de la discriminación racial y cultural a que eran sometidos los indios colombianos.

El mayor logro de Manuel Quintín Lame será el haber despertado la conciencia indígena y haber puesto en el orden político nacional la problemática económica y social de la condición indígena (Castrillón, 1973; Vasco, 2008). A nivel regional será recordado por su capacidad de concientización y movilización de las comunidades indígenas en los Departamentos del Cauca, Huila y Tolima; su lucha puso en tela de juicio el proceso mismo de "civilización de los naturales" (de colonización o domesticación propiamente dichos) emprendido por antiguos y modernos

da a la sustitución de importaciones; todo lo anterior cobijado bajo un escenario de guerra fría (1945-1989) del cual se desprenden no solo confrontaciones ideológicas sino también económicas, soportadas en modelos de desarrollo antagónicos. colonizadores, al punto que algunos llegan a definirle como alguien "inapropiado e inapropiable", en referencia a "[...] los márgenes del concepto totalizador y homogeneizante del "otro", de manera inapropiada e impropia, y que es inapropiable en tanto su subjetividad cultural y política reclama formas alternativas de representación y de lenguaje" (Espinosa, 2003: 140).

No obstante, es este carácter inapropiado e inapropiable de Manuel Quintín Lame el cual se repite en generaciones posteriores de indígenas en el Cauca, el que permite que se reclame no solo el territorio sino también la cultura como verdaderos refugios de la libertad y dignidad humana por parte de las comunidades indígenas. Es así como los pensamientos del indio que se educó dentro de las selvas colombianas rinden frutos posteriores mediante el proceso de resistencia y lucha en defensa de la unidad, el territorio, la autonomía y la cultura ${ }^{15}$, al constituirse en 1971 el Consejo Regional Indígena del Cauca -CRIC- como máxima organización indígena de lucha y resistencia.

\section{Conciencia de clase y conciencia histórica como referentes sociohistóricos}

Esta toma de conciencia de clase e histórica de la condición indígena no fue ajena a los habitantes de Puracé, ni mucho menos a los indígenas

15. Marco referencial de movilización del Consejo Regional Indígena del Cauca CRIC-. 
incorporados como obreros en la empresa Industrias Puracé S.A. Todo lo contrario, se sabe que algunos de los miembros del Resguardo Indígena de Puracé y ciertos trabajadores indígenas de la empresa minera fueron en su tiempo dirigentes del proceso de movilización, lucha y resistencia. Se destaca el caso de algunos obreros como Evelio Hernán Caldon, Anatolio Quira Guauña (1939-2004) y Luis Enrique Guauña, quienes llegaron a ser gobernadores del Cabildo del Resguardo Indígena de Puracé, concejeros mayores del Concejo Regional Indígena del Cauca -CRIC- y hasta diputados de la Asamblea del Departamento del Cauca.

Esta correlación entre conciencia de clase y conciencia histórica de la condición indígena conlleva a la unificación de intereses comunes entre los obreros indígenas y la comunidad indígena del Resguardo de Puracé. Un primer momento de esta unificación histórica de intereses acontece en 1973 cuando los obreros y la comunidad indígena presentan a la compañía Industrias Puracé S.A. un pliego de peticiones, reclamando: 1) mejores prácticas en la explotación minera, 2) compensaciones por las consecuencias sociales y ambientales causadas en la zona, 3) reconocimiento del Cabildo como autoridad tradicional indígena en el territorio y 4) uso preferencial de la mano de obra indígena en la mina de azufre El Vinagre en Puracé.

Un segundo momento acontece a finales de la década de 1970 cuando emerge el primer escenario de crisis y cierre temporal de la empresa; en esta oportunidad los obreros y la comunidad del Resguardo Indígena de Puracé reclamaron la intervención de los empresarios y del Gobierno Nacional en la solución de la problemática. En efecto, estos dos momentos permiten constituir un referente sociohistórico de lucha y resistencia obrera, indígena y campesina en Puracé, al postular al Gobierno (y por ende al Estado colombiano) como el actor principal en la solución de la crisis económica y social que genera el proceso de modernización económica.

A lo anterior se agrega el posterior reconocimiento e incorporación de la cultura ancestral en la sociedad nacional, igualmente el desarrollo y fortalecimiento de las prácticas socioeconómicas en contextos locales, como una estrategia de lucha y resistencia de las comunidades indígenas (Consejo Regional Indígena del Cauca, 1983). El proceso de resistencia y lucha en defensa de la unidad, la autonomía, el territorio y la cultura emprendido por el movimiento indígena en las primeras décadas del siglo XX terminó no solo en el reconocimiento de sus derechos, prácticas y costumbres culturales en la Asamblea Nacional Constituyente de 1991, sino también en la incorporación de sus instituciones sociales en las prácticas de gestión de lo público estatal contemporáneo. Los Resguardos dejaron de ser simples espacios territoriales de protección indígena para constituirse en entidades territoriales especiales en un contexto de 
reformas del ordenamiento territorial colombiano y de la gestión público/ estatal, con sus cabildos, gobernadores, secretarios, alcaldes y alguaciles como autoridades tradicionales de gobierno. Este avance en el ordenamiento institucional colombiano permitió a las comunidades indígenas participar en las rentas públicas del Estado, al mismo tiempo que planificar el desarrollo económico y social desde un sentido que ellos denominan como "propio, autónomo e independiente".

El proceso de resistencia y lucha en defensa de la unidad, autonomía, territorio y cultura dio origen al desarrollo y fortalecimiento de prácticas socioeconómicas "propias" de carácter autogestivo. Esta aspiración hacia una "economía propia" por parte de las comunidades indígenas en el Cauca sustentada en el uso cultural del territorio, la reciprocidad, la redistribución, el trabajo comunitario y la abstención de la acumulación, conllevó a que se experimentara por parte de sus miembros ciertos sentidos identitarios de libertad, autonomía y autogestión; asumiendo la producción de una manera responsable y autónoma, como una estrategia liberadora del proceso histórico de colonización y sometimiento, pero también, como un mecanismo de defensa, control y administración del territorio (Quijano, 2012). El trabajo comunitario a través de la minga, la ayuda mutua, el cambio de mano, entre otros; como un proceso particular de lucha y resistencia (Londoño, 2005), permitió la configuración de dinámicas de rela- cionamiento e integración social significativas, inspirando el surgimiento de distintas iniciativas organizativas de carácter político y socioeconómico de una manera relevante, importante y permanente.

Es así como surge en la territorialidad de Puracé un conjunto de expresiones y experiencias organizativas de tipo socioeconómico y político adscritas a procesos locales de lucha y resistencia las cuales se mimetizan en forma de una economía social y solidaria (Razeto, 1993; Price, 1998), pero también, a la manera de una economía tradicional indígena que se erige como una "economía propia", local o comunitaria (Londoño, 2005; Quijano, 2012; Vitonás, 2008). Se destacan las tiendas comunitarias, las cooperativas y asociaciones de productores gestionadas a través de mingas, el trabajo de mano, el trabajo comunitario; como también los intercambios y actividades de reciprocidad, a través de prácticas de trueque e intercambio no dinerario, espacios que motivan principios solidarios, comunitarios, redistributivos, no acumulativos y recíprocos; los cuales se complementan con emprendimientos socioeconómicos de tipo individual y colectivo. Los obreros indígenas de Industrias $\mathrm{Pu}-$ racé S.A. que constituyeron Emicauca S.A. no fueron indiferentes a este tipo de experiencias socioeconómicas y políticas colectivas, se sabe que en forma posterior a la constitución del sindicato, los trabajadores de la mina emprendieron la constitución de una cooperativa de comercialización en el 
marco del vínculo social y representativo generado al interior de la empresa.

Los cabildos han cumplido un papel importante en este tipo de experiencias organizativas al ser los encargados de la promoción del desarrollo y fortalecimiento de una "economía propia” al interior de los Resguardos. Este tipo de intervención local por parte de las comunidades a través de los Cabildos adquirió especial relevancia desde la Constitución Política de 1991, cuando los Resguardos como entidades territoriales indígenas entraron a percibir recursos públicos del Estado. Este acceso a los recursos estatales ha estado acompañado de la posibilidad de ejercer la planeación y el direccionamiento del desarrollo local de manera libre y autónoma, aspecto concretado por las comunidades indígenas a través de los denominados "planes de vida", mecanismos mediante los cuales las comunidades concretan sus aspiraciones del buen vivir de una manera participativa, autóctona y autónoma (Consejo Regional Indígena del Cauca, 2007).

Es este pasado sociohistórico el que determina el accionar social de los trabajadores indígenas de Indus- trias Puracé S.A. y la comunidad indígena del Resguardo de Puracé en la constitución de un nuevo emprendimiento denominado Emicauca S.A. El accionar de los obreros indígenas que constituyen Emicauca S.A. ha estado determinado no solo por el pasado social e histórico como militantes del sindicalismo obrero, sino también por el vínculo como integrantes de la comunidad del Resguardo Indígena de Puracé en calidad de comuneros y dirigentes. Es un pasado cargado de interacciones sociales, costumbres, acciones, conflictos, referentes e interpretaciones simbólicas, en forma de una historia común (pasado) propia de un grupo social específico, la cual permite la acción colectiva en el futuro/presente. Es este vínculo sociohistórico y el estado de inclemencia en que quedan los trabajadores indígenas ante el cierre de Industrias Puracé S.A. en 1996 el que permite que se destinen recursos públicos por parte del Cabildo de Puracé en la constitución de Emicauca S.A., como una iniciativa autogestionada por parte de sus trabajadores. La destinación de recursos públicos se constituye en un acto de lucha de los obreros indígenas y la comunidad entera en defensa del trabajo minero como única alternativa de vida y resistencia. 
Arboleda Suárez, E. (2019). Conciencia obrera y conciencia histórica como referentes sociohistóricos de autogestión en territorios del Cauca Indígena. Revista Estudios Latinoamericanos, 44-45, 121-136.

\section{Referencias}

Álvarez, V. (2001). Los documentos notariales como fuente para la historia empresarial: un ejemplo de aproximación empírica. Revista EAN (44).

Espinosa, M. (2003). El indio lobo. Manuel Quintín Lame en la Colombia moderna. Revista Colombiana de Antropología (39), 139-172.

Cajas, J. (1982). Industrias Puracé SA: sobre el proceso de transformación de indígenas a obreros y crisis medioambiental. Monografía Departamento de Antropología. Popayán: Universidad del Cauca.

Calle, D. (2009). Revive mina de azufre natural. UN Periódico (119), 19.

Castillo, G. (2004). Manuel Quintín Lame: luchador e intelectual indígena del siglo $\mathrm{XX}$. En: M, Lame. Los pensamientos del indio que se educó dentro de las selvas colombianas. Popayán: Editorial Universidad del Cauca.

Castrillón, D. (1973). El indio Quintín Lame. Bogotá: Tercer Mundo Editores.

Consejo Regional Indígena del Cauca (1983). Nuestras luchas de ayer y de hoy. Popayán: Cartilla del CRIC, No. 1.

Consejo Regional Indígena del Cauca (2007). Plan de vida regional de los pueblos indígenas del Cauca. Popayán: CRIC.

Lame, M. (2004). Los pensamientos del indio que se educó dentro de las selvas colombianas. Popayán: Editorial Universidad del Cauca.

Londoño, L. (2005). El Consejo Regional Indígena del Cauca-CRIC-. Historia de una organización indígena en su lucha por la tierra, el territorio y una "economía propia”. Material de apoyo Licenciatura en Etnoeducación. Popayán: Universidad del Cauca.

Marx, C. (1954). Salario, precio y ganancia. Moscú: Ediciones en lenguas extranjeras.

Price, R. (1998). Notas para una etnografía de los Kokonuko. Documento sin publicar. Popayán: Asociación de Cabildos Indígenas Genaro Sánchez.

Quijano, O. (2012). Ecosimías. Visiones y prácticas de diferenciación económico cultural en contextos de multiplicidad. Popayán: Editorial Universidad del Cauca, Universidad Andina Simón Bolívar.

Razeto, L. (1993). Los caminos de la economía de solidaridad. Santiago de Chile: Ediciones Vivarium. 
Ríos, J. (1998). Las teorías de las clases sociales de Marx y de Weber: introducción para estudiosos de la administración. Revista Contaduría y Administración (189).

Romero, F. (2006). Manuel Quintín Lame. El indígena ilustrado, el pensador indigenista. Popayán: Consejo Regional Indígena del Cauca.

Vasco, L. (2008). Quintín Lame: Resistencia y liberación. Tabula Rasa (9), 371-383.

Vitonás, E. (2008). Nuestra economía. Formas de producción y distribución de la economía nasa. Etnias y Política, (9), 140-153. 